\title{
ACERCA DE UN POSIBLE MALENTENDIDO SOBRE LA OBLIGACIÓN DE RECIPROCIDAD
}

\author{
Ignasi TERRADAS ${ }^{1}$
}

Abstract: The aim of this article is to think about an ethnographic misunderstanding and its results in anthropological theory. It is a datum brought by E.H. Man and subsequently incorporated by Claude Levi-Strauss and Annette Weiner in their theories about reciprocitty. I suggest that the good fortune of this misunderstanding owes much to its concomitance with the ideology of possessive individualism.

Resumen: El objeto de este articulo es reflexionar sobre un malentendido etnográfico y sus consecuencias para la teoría antropológica. Se trata de un dato aportado por E. H. Man que Claude Lévi-Strauss y Annette Weiner han incorporado de manera muy significativa a sus teorias de la reciprocidad. Sugerimos que la fortuna de este malentendido se debe a sus concomitancias con la ideologia del individualismo posesivo.

No nos referimos a un malentendido obstinado, sino a un malentendido casi accidental, a uno de esos "datos etnográficos" posiblemente descontextualizado. Nuestra intención es volverlo a comprender en su contexto histórico y etnográfico. Lo que nos ha motivado a ello es la influencia que este dato ha tenido al ser difundido como dato emblemático por dos notables teóricos de la reciprocidad, Claude Lévi-Strauss y Annette Weiner.

Antes de referirnos al malentendido concreto que nos ocupa, creemos que es mejor decir de qué clase de malentendido estamos hablando. Así alcanzare-

1 Proyecto de Investigación PB-98-1238. Programa Sectorial de Promoción General del Conocimiento.

ENDOXA: Series Filosóficas, n. ${ }^{\circ}$ 16, 2002, pp. 113-138. UNED, Madrid 
mos una idea más justa del mismo. Se trata de cómo al concebirse el concepto teórico de reciprocidad, se ha partido de una confusión entre su práctica excepcional y la normal, entre su opcionalidad más o menos ideal y su obligación gravosa , o también, entre su uso y su abuso. Al haber ocurrido esto, las interpretaciones teóricas han acudido a buscar explicaciones para la normalidad de lo anormal (reglas prescriptivas, "totalitarias", de reciprocidad, representando sociedades esclavizadas por la obligación de reciprocidad) , y a interpretar un dato etnográfico de Edward Horace Man sobre los andamaneses como una utopía de alcance universal que desea liberarse de la obligación de reciprocidad.

Proponemos una reconstrucción histórica y una contextualización etnográfica más precisa para dilucidar esta cuestión. ¿¿Ha existido realmente un deseo utópico para liberarse de la reciprocidad?.

Annette Weiner nos ha legado una obra ${ }^{2}$ cuya importancia no puede soslayarse, a pesar de las críticas que como la de Mark Mosko ${ }^{3}$ nosotros mismos suscribimos. En ella, inmediatamente después de criticar la "teoría antropológica a la búsqueda de universales, el enfoque positivista...." 4 , afirma que "todo intercambio está predicado por una paradoja universal, cómo guardar mientras se das. Sin preocuparse mucho por este enunciado universalista después de haber criticado el universalismo positivista, Weiner recoge y amplia una teorización de la reciprocidad de gran repercusión en la Antropología. Es la que reconoce en la reciprocidad una obligación persistente y una estrategia política y económica que caracteriza a muchas sociedades. Paradoja, contradicción o ambivalencia: el enunciado de Weiner se presta a lecturas muy convincentes de diversas prácticas sociales. La fórmula "guardar mientras se da" es altamente sugerente, tanto para una inversión de riqueza como para un acto de adhesión o afección humana, pongamos por caso. $\mathrm{Y}$ asimismo conlleva un mensaje claro para toda una tradición moral: si la práctica consiste en guardar mientras se da, en poder guardar mientras hay que dar, entonces, se entiende que no tener que dar permite guardar todo para uno mismo. En el seno de la sociedad

2 ANNETTE WEINER (1992): Inalienable Possessions. The paradox of keping while giving. Berkeley: University of California Press. G.

3 MARK MOSKO (2000): "Inalienable ethnography: keeping-while-giving and the Trobriand case" Journal of the Royal Anthropological Institute, n. ${ }^{\circ} 6$.

4 Id., op. cit., p. 5. 
dominada por el individualismo posesivo 5 , la idea de Weiner significa que dar es una obligación social que va en contra del deseo natural e individual de guardar. La fuerza de esa idea en el amplísimo contexto individualista dificulta comprenderla como estricta paradoja. Es esa interpretación individualista la que a nuestro parecer explicará la persistencia del malentendido etnográfico que a continuación referimos ${ }^{6}$.

Dice Weiner: «En el párrafo final de las Estructuras Elementales del Parentesco, Claude Lévi-Strauss describe un sueño universal expresado en un mito de una isla andamanesa, el cual habla de «un mundo en el cual uno puede guardarse lo suyo" y escapar de "la ley del intercambio" 7 .

Un sueño universal: fijémonos en el alcance semántico de ambos términos. La utopía, la sociedad finalmente feliz y con una liberación válida para todo el mundo. La liberación de la obligación del don y la reciprocidad. El sueño universal es pues el cumplimiento del individualismo posesivo, guardar todo sin tener que dar nada. Y el intercambio es percibido como una ley que va contra lo natural de guardarse cada uno lo suyo. Pensemos que esta lectura puede hacerse fácilmente paralela con la supuesta naturalidad del otro intercambio, el del mercado. Así, mientras los primitivos se quejarían de la obligatoriedad del intercambio, de la exigencia del don o de la reciprocidad, los occidentales brindarían un intercambio natural, sin coacciones, que se ajustaría al deseado por los primitivos. En otras palabras: el mercado sería la naturaleza utópica a la que se llegaría con la abrogación de la "ley del intercambio". Así el mercado como encuentro de oferta y demanda sería más natural que la reciprocidad como encuentro de dar, recibir y devolver. Como si tener que comprar y vender para vivir fuera más natural que dar $\mathrm{y}$ devolver.

Pero la fuente etnográfica dista mucho de corroborar estas interpretaciones. En principio, lo que dice Lévi-Strauss procede de un fragmento de Edward

5 De acuerdo con Crawford Brough Macpherson entendemos por individualismo posesivo la ideología que legitima la propiedad privada según el derecho natural y que al mismo tiempo niega el derecho natural fuera de esta misma propiedad. Por lo demás, ahora no nos interesa si esta ideología correspondió o no a Locke, tal como Macpherson trata de demostrar. Lo que sí nos interesa, antropológicamente, es la trascendencia capitalista de esta idea y actitud: naturalización de la propiedad como capital y desnaturalización de lo que no existe como capital. Cf. Crawford Brough Macpherson (1962): The Political Theory of Possessive Individualism. Oxford U.P.

6 WEINER, op. cit., p. 6.

7 WEINER, op. cit., p. 6. 
Horace Man - muy descontextualizado como veremos luego- y que encabeza la Conclusión de Las Estructuras elementales del Parentesco. El texto de Lévi-Strauss dice así: «La vida futura será la repetición de la vida terrestre, salvo en que todo el mundo permanecerá joven, la enfermedad y la muerte serán desconocidas , y nadie se casará ni será dado en matrimonion" ${ }^{8}$. $\mathrm{Y}$ al final de su libro, en base a esta cita, Lévi-Strauss concluye : " el mito andamanés de la vida futura... describiendo la beatitud del más allá como un cielo en el que las mujeres ya no serán intercambiadas; es decir, rechazando, en un futuro o en un pasado, igual de inalcanzables, la dulzura, eternamente negada al hombre social, de un mundo en el que se podría vivir entre uno mismo (entre sol)" ?.

Por lo tanto, aunque Lévi-Strauss no dice exactamente lo que Weiner pretende, "guardarse lo suyo" y escapar a la «ley del intercambio", sí que también usa el "mito andamanés» para representar la suficiencia natural del individualismo. Lo «natural individual" basta para una imaginación de lo social. Por lo demás, hay que tener presente que Lévi-Strauss no sustrae su teoría del intercambio y la alianza fuera del marco del Parentesco.

El uso que hace Lévi-Strauss del "mito" andamanés es a favor de la realización de la sociedad "entre uno mismo", por oposición a la sociabilidad manifiesta en la práctica y en la imaginación de las posibilidades matrimoniales. El objetivo es hacer la sociedad sin matrimonios, hacerla individualmente con la imaginación, con la cabeza, a la manera del intelectual utópico occidental, algo que suena muy poco andamanés.

Pero si nos acercamos más a la fuente etnográfica del supuesto "mito" nos daremos cuenta de que éste se refiere al emparentamiento de manera muy específica y no tiene que ver con su negación total, sino con un hecho distinto, nada utópico: una preferencia endogámica. Es decir, que el tema etnográfico que ha sido fuente de un malentendido considerable, ni iba contra el principio de reciprocidad, ni contra el establecimiento del matrimonio, ni era un sueño individualista.

¿Qué dice en realidad la fuente etnográfica?. Lévi-Strauss toma su cita de las páginas 94-95 del capítulo que Edward Horace Man ${ }^{10}$ dedica a «Creencias relip. 525 .

8 Cl. LÉVI-STrauss (1967): Les Structures Elementaires de la Parente. París: Mouton.

9 Id., op. cit., p. 570. 
giosas y demonología", no del siguiente dedicado precisamente a la "Mitología». Man, expone en la sección 27 de dicho capítulo que los andamaneses han dicho que en "la resurrección "1 se reunirán todos y vivirán para siempre en una nueva tierra», y que las "almas de los malvados serán castigadas a fin de ser reformadas" en una especie de purgatorio que los andamaneses mencionaron con un nombre indígena. A continuación ${ }^{12}$, Man dice lo que Lévi-Strauss cita, salvo que el párrafo sigue así: «los animales, pájaros y peces también reaparecerán en el nuevo mundo en su forma presente» ${ }^{13}$. Luego, en la sección 29 se dice que "Este estado de felicidad será inaugurado con un gran terremoto, ordenado por Puluga...".

Ni Weiner ni Lévi-Strauss parecen haber cotejado esta información de Man con la que sin duda podemos caracterizar como la monografía principal de los andamaneses, la de Radcliffe-Brown ${ }^{14}$. En "Los isleños de Andamán" ya se advierte que Man no duda en presentar algunas creencias andamanesas «aproximadamente cercanas a la verdadera fe" ${ }^{15}$ (la cristiana se entiende). Luego, en una nota ${ }^{16}$, Radcliffe-Brown advierte más claramente, con respeto y ponderación, que Man estuvo «influenciado sin duda por un deseo muy fuerte de mostrar que las creencias de los andamaneses sobre Puluga ${ }^{17}$ eran realmente, en lo fundamental, las mismas que las creencias de los cristianos sobre Dios. Ciertamente, Man no dejó que este deseo afectara su recopilación de creencias andamanesas, pero es muy improbable que inconscientemente no ejerciera una influencia notable tanto sobre Mr. Man como sobre sus informantes". Tampoco hay que olvidar que estos informantes eran los andamaneses que Man «recogía» en una especie de internado dónde se trataba de "educarlos» e instruirlos en la "verdadera religión".

Si vamos a la Biblia ${ }^{18}$ y buscamos la doctrina de la resurrección nos encontramos con los temas que Man atribuye a los andamaneses:

10 EDWARD HORACE MAN (1932) (1885): On the Aboriginal Inhabitants of the Andaman Islands. Londres: Royal Anthropological Institute.

11 Cursiva nuestro.

12 Sección 28.

13 Man, op. cit., p. 95.

14 RadCliffe-Brown, A.R. (1964) (1922): The Andaman Islanders. New York: The Free Press. También: A.R. Radcliffe-Brown (1910). "Andamans. Puluga». Man. 2,17.

15 Palabras de Man, citadas por Radcliffe-Brown en The Andaman Islanders, pp. 157-158.

16 (1964) (1922), op. cit., p. 370.

17 Gran espíritu o deidad destacada en el mito y el ritual.

18 Versículos cotejados en La Sainte Bible (1961). París: Les éditions du Cerf. Y LA BIBLIA. Versió dels textos originals $i$ comentari (v. f.) Monestir de Montserrat. 
— «Nueva Tierra» (Isaías 65,17; Isaías 66,22; Apocalipsis 21,1).

- En la Resurrección se reunirán todos (vivos y muertos) (Pablo,1 Tesalonicenses 4,16-17).

- Las almas de los malvados serán castigadas (Juicio Final): en Man aparece como tema del purgatorio (postbíblico) que se conoce con un término nativo que Man no traduce ni comenta.

- «Se permanecerá joven" (Isaías 65,20). El estado de felicidad inaugurado por un gran terremoto es un tema recurrente en la escatología bíblica, aunque la inversión posterior y la rotura de la conexión entre el cielo y la tierra son típicamente andamanesas.

- "Nadie se casará ni será dado en matrimonio": «En la resurrección, en efecto, no se toma ni mujer ni marido, sino que se es como los ángeles en el cielo" (Mateo 23,30; Marcos 12,25). Esta es la respuesta que Jesús dio a los saduceos cuando le preguntaron de quién sería esposa una mujer que siguiendo el levirato se había casado con varios hermanos. En Lucas $(20,34)$ se dice : «Los hijos de este mundo toman mujer o marido; pero los que habrán sido juzgados dignos del otro mundo y de la resurrección entre los muertos no toman ni mujer ni marido».

— «Animales, pájaros y peces reaparecerán» (versión de Man): «Ganado, pájaros y peces" : este orden es el que se halla en el modo de resurrección expuesto por Pablo (1 Corintios 15,39).

Parece bastante fundada la sospecha de que el «mito» ${ }^{19}$ en cuestión, procede más de la Biblia que de la cultura religiosa andamanesa de aquella época.

Con el andar del tiempo se podría haber producido el sincretismo precipitado por el mismo Man... Pero unos datos posteriores de Vishvajit Pandya ${ }^{20}$ pueden arrojarnos nueva luz sobre esta cuestión. Estos apuntan a desacreditar la existencia de una creencia andamanesa en esa parusía liberadora del intercambio y de la obligación de reciprocidad en el emparentamiento.

Pandya sí que nos proporciona una narración mítica propiamente dicha, y aunque un siglo posterior a la creencia de Man, encaja mucho más específica-

19 En realidad el texto de Man indica una creencia, no narra un mito.

20 VishVajIT Pandya (1993), Above the Forest. Delhi: Oxford U.P. 
mente con la historia social andamanesa que la supuesta doctrina universal de liberación de la obligación de reciprocidad en el emparentamiento.

La narración que transcribe Pandya, hallada en 1983, podría ser muy parecida a la que en realidad alcanzó a Man entre 1869 y 1880, puesto que muy significativamente se refiere al impacto colonizador en el asentamiento andamanés. Esta narración es un relato histórico-mitológico que trata el impacto de la colonización en el seno de la historia religiosa andamanesa, que es básicamente la de la comunicación entre humanos y espíritus, entre vivos y muertos.

Se trata del mito $n .^{\circ} 1^{21}$ que Pandya divide en 9 secuencias ${ }^{22}$ y que le fue narrado por Tambolaie.

En la secuencia H, Tambolaie expone la creencia en cuestión: «Nadie morirá y no habrá espíritus. No habrá matrimonio ni se darán los jóvenes a los ancianos y a los espíritus (en el ritual de iniciación)".

Veamos todo el contexto de esta aseveración.

La narración comienza evocando una expedición tradicional (en contraste con el presente) a un lugar remoto de las islas, cuando "por entonces las estaciones eran buenas", y en la expedición participaban hombres, mujeres y niños, viajando en una gran canoa. Fue entonces cuando hallaron en ese lugar abundantes huevos de tortuga. Recogieron tantos como pudieron y esto significó una ofensa para los espíritus.

Ante esta recolección abusiva, los espíritus decidieron restringir dichos alimentos y repartir en diferentes estaciones las tortugas y los huevos de tortuga.

Más tarde, con la misma gran canoa, fueron hasta el asentamiento de los blancos y obtuvieron de ellos té y tabaco. Hallaron gustosos ambos productos y abandonaron sus productos nativos, los que hasta entonces constituían su bebida y su pipa tradicionales. Fueron las mujeres, quienes especialmente requirieron a los hombres para que siguieran yendo con frecuencia al asentamiento de los blancos para obtener té y tabaco.

Fijémonos que se habla de dos expediciones de carácter extraordinario a lugares lejanos que poseen o poseían determinados recursos en abundancia. La

21 Op. cit., pp. 7-8.

22 Id. Nota 5, p. 7. 
primera expedición es en tiempos andamaneses y señala el paso de una recolección tipo "país de la cucaña" a otra más realista, sujeta a las fluctuaciones estacionales. Los espíritus habrían introducido este cambio.

La segunda expedición ya es en tiempos coloniales, y en vez de la abundancia de un producto nativo (huevos de tortuga) descubierta en un lugar remoto ("país de cucaña») y en un tiempo utópico (sin estaciones), se descubre la abundancia de dos productos exóticos poseídos por los blancos y otorgados por éstos a los andamaneses.

La narración sigue: un día, algunas mujeres jóvenes fueron con los hombres al enclave colonizador. Los espíritus se enojaron mucho por este hecho y provocaron una tempestad en la que naufragaron todos, no hubo supervivientes. Con lo cual ya no quedaron hombres adultos y muy pocas mujeres jóvenes ${ }^{23}$. Entonces los jóvenes decidieron casarse con mujeres mayores, y así hubieron de casarse con las hermanas de sus padres y con otras mujeres de la casa de las hermanas de sus padres (primas cruzadas patrilaterales). Este es el matrimonio concebido como de obligación social.

La historia aparece en toda esta narración reinterpretada con el fondo mitológico. $\mathrm{Y}$ en esta conjunción aparece explicada la regla matrimonial.

Por otra parte, la narración de Tambolaie procede de la población Onge de la Pequeña Andamán. Los onges debían atravesar el Paso de Duncan para llegar al enclave colonizador de Port-Blair en una tierra que era de los Jarawa y Aka-Bea. Pero la lógica histórica que nos da Tambolaie concuerda perfectamente con lo ocurrido en el conjunto de las Andamán.

La mito-lógica de Tambolaie nos dice que los males que se ceban sobre los andamaneses son causados por los espíritus, quienes están muy enojados por la sustitución de los bienes del bosque andamanés por los del hombre blanco. Se trata de una alteración de la reciprocidad tradicional entre espíritus y humanos: los bosques y las costas (como en la primera parte del mito) estaban sujetos a una explotación estacional repartida entre los espíritus y los humanos. La irrup-

23 Todo este episodio refleja la fuerte mortalidad introducida por el contacto con el hombre blanco y la extensión de la sífilis y otras enfermedades al infectar los hombres del penal británico a las mujeres andamanesas. Sobre el etnocidio andamanés cf. Nota 3 pág. 48 de Ignasi Terradas "Les cigales et le rythme des jours" en École Pratique des Hautes Etudes, Biologie. et. Evolution des Insectes, 11/12,1998/1999. 
ción de los blancos con sus mercancías destruía el régimen de alternancia estacional. En éste, se suponía que un exceso de recolección ${ }^{24}$ era un robo (quitar sin devolver) a los espíritus. Y que también, el desprecio hacia lo que ellos dejaban para los humanos (hierbas para fumar e ingerir, en vez del té y el tabaco) en la temporada que les era asignada, constituía una ofensa a la reciprocidad debida entre vivos y muertos. Se descuidaba especialmente el saber aceptar los dones de los espíritus. Sustituirlos con los dones de los blancos era traicionar la reciprocidad básica que daba vida a todo el ritual y cosmovisión andamanesa.

Así pues, los andamaneses habrían traicionado la base de su moral religiosa ${ }^{25}$ al obtener de los blancos unos productos a expensas de los que como dones estaban vinculados a la comunicación con los espíritus. Y al mismo tiempo, la comunicación con los blancos se hacía en detrimento de la comunicación con los espíritus, el tráfico sustituía el ritual, los regalos de la colonización sustituían a los dones de la tradición.

El nuevo contacto destruía al anterior. El resultado no podía ser otro que la enfermedad y la muerte. Los espíritus ocasionaban malos encuentros ${ }^{26}$ con quienes no establecían las relaciones adecuadas con ellos. El mundo de los muertos crecía y el de los vivos disminuía. La mortalidad resultó más evidente entre los grupos que más habían intercambiado con los colonizadores. Y la población más proclive a los contactos con los blancos eran los adultos y las mujeres jóvenes (luego la narración se hará más explícita al respecto).

En este contexto de crisis demográfica, el matrimonio con tías y primas cruzadas patrilaterales significa la imposición de una norma nueva de alianza (entre lugares más dispersos) para hacer frente a la escasez de población. Es decir, que ante la falta de mujeres núbiles en el propio poblado (el mito lo aclara después), el matrimonio se instituyó preferentemente con las primas (o tías) cruzadas patrilaterales.

La norma matrimonial hallada por Pandya ${ }^{27}$ encaja con la narración mítica. El matrimonio de un hombre con una pariente patrilateral supone lo siguiente:

24 Y más aún si se hacía fuera de la temporada señalada para ello.

25 Con notables consecuencias ecológicas desde la perspectiva de la sostenibilidad.

26 Malabuka en onge.

27 Op. cit., p. 21. 
A) El traslado del hombre al poblado de su esposa, traslado desde sus consanguíneos matrilineales (madre y avúnculo, esencialmente) a sus consanguíneos patrilineales, encontrándose normalmente su padre allí por igual motivo.

B) Contribución económica del hombre, a partir del matrimonio, a su grupo patrilateral. Arraigo permanente de la mujer en su grupo matrilineal, dónde recibe a su esposo que le es primo cruzado matrilateral.

C) Radcliffe-Brown halló la práctica de adopción sistemática entre los andamaneses. Si ensamblamos esta práctica con las reglas descubiertas por Pandya, daría que los niños y las niñas serían adoptados por sus avúnculos ${ }^{28}$. Con lo cual, los niños -durante este período de adopción hasta la edad núbilirían a vivir al territorio de otro clan y en otro ecosistema (costa o bosque), y este territorio sería el mismo donde los chicos seguirían viviendo una vez casados. Es decir que para los hombres, aunque el avínculo no sería su suegro ${ }^{29}$, al pasar a ser educados por el avúnculo, lo eran en el lugar y circunstancias requeridas para su vida de casados. No vivían sin embargo con los padres de su futura mujer. En cambio, en el período adoptivo, las niñas sí que vivían con los padres de sus futuros maridos, y vivían también con sus propios hermanos. Se hospedaban en un clan y en unas tierras y con la familia de su futuro marido, pero volverían a residir a partir del matrimonio en el lugar dónde habían nacido.

D) El carácter recíproco de las visitas de hospitalidad andamanesa ${ }^{30}$ sería pues básicamente entre los padres, quienes al visitar a sus hijos adoptados temporalmente, irían a visitar a la familia del hermano de la madre, con lo cual, entre hombres, el avúnculo de los hijos o cunado del marido haría siempre de anfitrión, y el padre de los hijos de la hermana, de huésped. Aunque, en realidad, esta visita se hacía en el clan y territorio de nacimiento del padre, puesto que si al casarse, los hombres pasaban a residir uxoricalmente, entonces el avúnculo se encontraba viviendo en el pueblo de su esposa, el cual coincidía con el de nacimiento del padre de los niños adoptados. De este modo, el hijo

28 Según Pandya serían adoptados a partir de los cuatro años $(1993,23)$ y según RadcliffeBrown a partir de los 7-8 ańos $(1922,72)$ o a partir de los 9-10 años $(1964,78)$.

29 Quizá por este motivo Radcliffe-Brown descartó algo precipitadamente alguna norma matrimonial con otros primos cruzados.

30 Las que menciona Marcel Mauss (1950) (1923-24) en su Essai sur le Don. París: P.U.F., p. 173. 
tomaba esposa en este lugar y así pasaba a residir dónde nació su padre. Y la hija tomaba esposo en el mismo lugar y familia de adopción, pero ambos pasaban a vivir allí dónde ella nació, así como su madre y hermanos, pero no su padre. Con lo cual, los hijos eran educados en el transcurso de la adopción en el mismo sitio en el que residirían al casarse y dónde también habían nacido sus padres: la adopción y el matrimonio los incorporaban al lugar y al matrilinaje del padre, aunque se casaran con mujeres del patrilinaje ${ }^{31}$. En cambio, las hijas solamente se incorporarían al linaje y lugar paternos durante la adopción, y luego, al casarse, regresarían allí dónde habían nacido, al lugar del matrilinaje de sus madres que era también su residencia conyugal.

Nos hallamos pues con un mecanismo de alianzas paralelas y restringidas entre clanes divididos en poblados de costa y de interior. Con una trabazón social algo complicada para nosotros, típica de las civilizaciones cuya ingeniosidad social ha desarrollado el Parentesco y no el Estado. En resumen: se trata de un sistema exogámico local, de clan y de parentesco, y va unido a una práctica muy determinada de la hospitalidad en el seno mismo del Parentesco clasificatorio. Tanto el matrimonio como la hospitalidad contribuyen a formular por igual la versión andamanesa de la alianza.

Prosigamos ahora con la narración de Tambolaie:

Los hombres blancos fueron hasta la Pequeña Andamán con el objetivo de obsequiar con sus hojas de té y tabaco a los hombres y especialmente a sus mujeres. Al no encontrar a éstas ${ }^{32}$, los blancos se niegan a regalar sus hojas. La pretensión de los colonizadores de llevarse las mujeres y algunos hombres hasta uno de sus emplazamientos, la resistencia de los indígenas, y a la vez, la nueva dependencia establecida con el tabaco ( $y$ con el aguardiente, aunque quizás por pudor no se menciona en el mito) dieron lugar a un choque violento.

Tambolaie sigue narrando estos hechos, tomando aún a los espíritus como gobernantes del destino en el que ocurren estos malos encuentros (malabuka). Estos se achacan a faltas cometidas contra el tradicional eco-ritual andamanés, al dejarse seducir por los regalos de los colonizadores, quienes comenzaron

31 Esto da lugar a lo que Pandya llama "colapso" o desplome del matrilinaje sobre el patrilinaje con la adopción avuncular y el posterior matrimonio.

32 Se supone que los blancos buscan relaciones sexuales, como en la anterior sección de esta narración en la que las mujeres jóvenes ya no regresan de la tierra ocupada por los blancos. 
regalando cosas desde su emplazamiento, al igual que los espíritus, pero a diferencia de ellos no lo cedían en alternancia estacional, y, claro está, tampoco cedían los alimentos que el espacio de su enclave habría producido.

Luego, en otra secuencia del mito ${ }^{33}$, se relaciona el estado de cosas de la colonización (morbilidad, mortalidad, desocupaciones forzadas, crisis de los eco-rituales) con el refuerzo o imposición más exclusiva de la regla matrimonial FZD=MBS ${ }^{34}$ : «Esta es la manera como los onges van de un pariente a otro y evitan la hostilidad y la guerra» ${ }^{35}$.

Hasta aquí caben dos interpretaciones: o bien la regla FZD = MBS es una innovación estratégica para hacer frente a nuevas condiciones demográficas, económicas y políticas, y también para obtener una solidaridad más amplia frente a los invasores coloniales; o bien, dicha regla ya se practicaba antes pero con menos exigencia, constituyéndose en un tipo ideal de matrimonio sin un carácter netamente prescriptivo. Luego, con las circunstancias coloniales se impondría ya con ese carácter para conseguir una cooperación económica más estrecha (entre costa e interior) y mayor solidaridad política.

Esta segunda interpretación nos parece la más correcta. Porque sería difícil imaginar todo eso durante el corto período de la colonización: la invención de un sistema de clanes con mitades residenciales, matriclanes matrilocales y exogamia cruzada patrilateral, algo propio del desarrollo histórico de los Parentescos clasificatorios. Este sistema se vería en parte debilitado y en parte reforzado como defensa social frente al impacto mortal de la colonización.

Después, Tambolaie expone el fragmento relativo al futuro paraíso andamanés ${ }^{36}$. Este aparece más bien por contraste con la mayor obligatoriedad de la regla matrimonial que hace frente a la crisis creada por los colonizadores extranjeros. La crisis de colonización consistía, no lo olvidemos, en una morbilidad sin precedentes, la mortalidad resultante, los choques violentos, la deportación ${ }^{37}$ y un sentimiento de culpa hacia los espíritus de los antepasados,

33 La $G$ en el texto de Pandya.

34 Hija de la hermana del padre con hijo del hermano de la madre.

35 Es lo que Lévi-Strauss ha denominado la conversión de parientes en aliados, cuestión clave en el Parentesco clasificatorio como orden e ideología política.

36 Secuencia H en Pandya, op. cit.

37 Incluyendo la deportación o "visita forzada" de algunos andamaneses al continente indio para convertirlos a las maravillas de la civilización, cosa que no obtuvo éxito. 
entendiendo que mientras existiera un mundo andamanés, ellos, los muertos, cada vez más numerosos, requerían una comunicación -los ecorituales- que por las mismas circunstancias de la colonización no se podía realizar de manera justa y recíproca.

Entonces, en este contexto, un futuro liberado de esa opresión, se percibe tanto en términos de liberación de los males de la colonización como de lo que se tuvo que exagerar del propio orden social, imponer con más obligatoriedad, con tal de resistirlos.

Con la persistencia de la invasión colonial la vida se tornó más pendiente de la muerte: de los encuentros con los espíritus. Éstos, cada vez en mayor número, reclamaban más de los vivos, les acechaban, produciéndose los malos encuentros (malabuka) que acarreaban la muerte. En definitiva, tan pocos vivos no podían satisfacer a tantos muertos según los cánones estacionales de la reciprocidad. Esto ha seguido explicando en términos de ética y religión andamanesas el por qué de su creciente desaparición.

Es así como la sociedad se tornó más dependiente de la solidaridad económica y social proporcionada con la mayor exigencia de la alianza patrilateral cruzada. El hecho de que Tambolaie no hable sólo del matrimonio FZD = $\mathrm{MBS}$, sino también de $\mathrm{FZ}=\mathrm{MBS}^{38}$ puede explicarse fácilmente (el mito lo relaciona así) con el aumento de la mortalidad de hombres y mujeres jóvenes más en contacto con los colonizadores.

Es así como la secuencia $\mathrm{H}$ del mito-historia de Tambolaie dice: que un día desaparecerán todos los fósiles de los muertos, las rocas en el mar, que nadie irá ni vendrá en viajes con los barcos de los blancos, ni en tránsitos de muerte (ambos se hacen equivalentes). Que se beberán y fumarán las sustancias del bosque andamanés. Que las enfermedades desaparecerán. Que ya no habrán más espíritus enojados, puesto que ya no morirá nadie más. Todo el mundo permanecerá joven. Los espíritus ya no serán requeridos, ni éstos requerirán a los vivos. "Nadie morirá ni habrán espíritus. No habrá matrimonio ni se darán los novicios a los ancianos y a los espíritus» ${ }^{39}$. He aquí la famosa frase otra vez. Pero sigamos con la conclusión del mito-historia, no sin

$38 \quad \mathrm{FZD}=$ MBS: Hija de la hermana del padre con hijo del hermano de la madre. $\mathrm{FZ}=$ MBS : hermana del padre con hijo del hermano de la madre.

39 En los ecorituales de iniciación personal y estreno estacional. 
antes aclarar, para ser añadido a lo que después diremos, que tal como muestra Pandya ${ }^{40}$, la esposa es imprescindible para que los hombres como novicios efectúen sus rituales de iniciación y transacción de los bienes estacionales $(=$ ecoritual) con los espíritus.

Sigue la secuencia $I^{41}$ : ahora se intercambian los jóvenes entre las poblaciones de la costa y las del interior (exogamia local y patrilateral cruzada). Al desaparecer los muertos fósiles, quedarán muchos jóvenes vivos (al no ser requeridos por tantos antepasados muertos: no se trata pues de una resurrección). No habrá motivo para temer la persecución de tantos espíritus como ahora se teme. Los habitantes de la costa y los del interior serán autosuficientes en jóvenes de ambos sexos y no tendrán que intercambiarlos obligatoriamente

Y aquí viene la conclusión de la narración de Tambolaie y que debe conjugarse con la aparentemente contradictoria de la anterior secuencia (la supresión del matrimonio). Dice así:" No habrá muerte ni necesidad de casarse fuera. Cada cual tendrá un esposo y nadie tendrá que ir a la población de su esposa para casarsen ${ }^{42}$. Así pues, sí que habrá matrimonio, lo que no habrá es el imperativo exogámico patrilateral y uxorilocal.

Ahora bien, para explicar mejor el significado de este mito-historia dividimos el argumento y la interpretación en diez puntos. De esta manera, la narración de Tambolaie nos informa de que:

1. La situación de mayor hostilidad entre vivos y espíritus coincide con el impacto de la colonización y el penal británico de Port Blair.

2. La hostilidad tradicional radicaba en excesos cometidos por los vivos en la recolección, no respetando lugares y temporadas ocupadas por los espíritus (tabúes asociados a los ecorituales).

3. La muerte de los andamaneses continúa dirigida por los espíritus durante los tiempos de la colonización, puesto que la multitud de espíritus va en aumento y las malabukas (malos encuentros) también resultan más frecuentes, con lo cual muere más gente.

40 Op. cit., capítulo 6.

41 Pandya, 1993, 8.

42 Pandya, 1993, 8. 
4. La razón principal de esta nueva hostilidad de los espíritus es la dependencia que los andamaneses han desarrollado con los colonizadores y sus productos, en detrimento de la reciprocidad con los espíritus, el cánon andamanés para obtener los alimentos estacionales.

5. Se instituye con más rigor la fórmula matrimonial $F Z D=M B S$. Con ello se entiende la necesidad de reforzar la exogamia interlocal. La finalidad parece ser la de obtener mayor ayuda económica (mayor complementación entre los grupos de la costa y los del interior ${ }^{43}$ ) y solidaridad política. Podría haber ocurrido que la formulación imperativa de la regla matrimonial patrilateral hiciera creer que era propia de entonces, que su práctica como abuso se volviera en contra de su tradición de uso. Es normal que se considere propio de un presente aquello que habiendo existido anteriormente, deviene más gravoso en la actualidad. Ya hemos dicho que las implicaciones de esta formula matrimonial parece que hubieran podido inventarse a raíz del impacto colonizador.

6. Los ofrecimientos sexuales de las jóvenes andamanesas, que son interpretados en clave de prostitución por los colonizadores, son percibidos como dañinos por los andamaneses. Los espíritus se sienten ofendidos por ello.

7. Ante los malos encuentros (malabuka) de blancos y espíritus con los humanos, surge la visión de un paraíso liberado. La narración de Tambolaie nos aclara que este paraíso no es el paraíso bíblico de Man, sino el de la misma tierra andamanesa liberada de la muerte, y repleta de juventud. Es una reacción contra el genocidio y el etnocidio, no contra la reciprocidad.

8. La secuencia final (I) es la que concluye ratificando el significado indígena andamanés de este mito-historia. Los jóvenes vivirán y ya no se verán los signos de su muerte, aquellas petrificaciones que como fósiles les recuerdan en el mar. No será necesario ocultarse del acecho de los espíritus. Y en vez de casarse obligatoriamente los de la costa con los del interior, habrá gente suficiente, y no habrá motivo para no poder casarse también entre ellos mismos. Ni muerte pues, ni exogamia prescriptiva para todos. Pero sí matrimonio, desde luego: «Cada uno tendrá un esposo y nadie deberá ir al lugar de su esposa para casarse". Con lo cual, lejos de negar el matrimonio y la reciprocidad,

43 Esto significa frutos, tubérculos, miel y cerdos del interior, y crustáceos, pescado, tortugas, dugongs, y también algunos frutos de la costa. 
se afirman, para realizarse fuera de la crisis colonial. El uno sin obligatoriedad exogámica y la otra sin tanta muerte.

La narración de Tambolaie no presenta pues exactamente una utopía andamanesa, sino más bien un correctivo ideológico a los excesos producidos por el impacto colonial. No predica tanto el fin del matrimonio como la mitigación de la obligatoriedad de una práctica exogámica. Lo que viene a decir es que no habrá necesidad de matrimonio bajo un régimen exogámico obligatorio si desaparece la hostilidad extraordinaria de los espíritus, los cuales al constituir una enorme legión frente a los vivos, se revelaban necesariamente faltos de atenciones recíprocas y reaccionaban "causando" aún más muertes. Pero luego, en el futuro positivo desaparecen los blancos y la muerte omnipresente y también la obligación forzada del matrimonio patrilateral de los hombres.

La recuperación del régimen tradicional de libertad en el emparentamiento daría lugar a la práctica que todavía observaban bastantes andamaneses en la época de Radcliffe-Brown. Su constatación resume perfectamente toda la transición histórica que hemos planteado: "Un hombre puede casarse con una mujer de un grupo local o de otro, de su tribu o de otra. Que el matrimonio entre personas pertenecientes al mismo grupo local ocurrió en una época anterior, lo pude comprobar con certeza, pero no fui capaz de determinar la proporción de estos matrimonios para el totab) ${ }^{44}$. Así pues, si antes los hombres se casaban más en el lugar en que habían nacido, ello quiere decir que la patrilinealidad jugaría un papel distinto respecto a la matrilinealidad tal como luego prevaleció en conjunción con la exogamia patrilateral. Pero a partir de aquí todo razonamiento sería pura conjetura.

Este replanteamiento que proponemos del dato etnográfico de Man nos parece que pone a su vez en entredicho la tendencia interpretativa que hallamos en obras como la de Weiner ${ }^{45}$ : tomar una reacción histórica y que debe interpretarse en su contexto específico como si se tratara de un ideal utópico, absolutamente radical, escatológico, fuera de la misma historia.

Toda la tesis del libro de Annette Weiner descansa sobre la premisa de una negación real de la reciprocidad en determinadas sociedades -en el entendido de considerarla gravosa- , y a la vez, acudir a ella, dando lugar a lo que Weiner denomina la paradoja de guardar mientras hay que dar.

44 Radcliffe-Brown (1964) (1922): The Andaman Islanders, p. 73.

45 Inalienable Possessions, op. cit. 
A nosotros nos parece que este enunciado teórico es falaz: se trasmuta a sociedades regidas por el principio de la reciprocidad la esperanza de librarse de dicho principio, como si les pesara por querer ser individualistas y librecambistas a la manera occidental. El ejemplo andamanés muestra lo contrario: les pesa un exceso de la regla de reciprocidad precisamente por culpa del impacto colonial, y rechazan la falta de reciprocidad que los blancos les quieren introducir por estimar que es una ofensa gravísima contra sus espíritus, y que es la que en realidad - también al claudicar los andamaneses colaboracionistas- causa la muerte de la vida humana y social del pueblo andamanés.

Resulta significativo que la teoría de ese querer librarse de la reciprocidad haya ido aparejada con la representación de la inalienabilidad de las cosas preciadas. Es decir que la argumentación de Weiner conjuga en su trasfondo ideológico el individualismo librecambista con el posesivo y atesorador. Esta es una conjunción típica de la Economía política capitalista. No es nada contradictoria: el beneficio comercial y la propiedad privada resuelven la contradicción aparente.

Ahora bien, la argumentación de Weiner confunde la «inalienabilidad» de objetos de gran valor simbólico con la de gran valor de cambio. No es lo mismo la joya que simboliza un poder, acaso un imperio, que juega un papel específico de prenda en la sucesión política y de rúbrica para una ley o un mandato, no es lo mismo decimos, que otra joya que simboliza un vínculo de familia o de amor, cuya alienación va aparejada con la destrucción de ese vínculo o con un gran revés de la fortuna, $y$ tampoco es lo mismo que la provisional "inalienabilidad" de otra joya adquirida como valor seguro ante las fluctuaciones monetarias o de otras mercancías, y que en su oportuno momento puede realizar toda la razón de su adquisición en el mercado.

Las generalizaciones que criticamos proceden de la concepción de la reciprocidad como dogma análogo al dogma del librecambio. De hecho, no pueden compararse directamente los estragos sociales causados por el dogma librecambista (incluyendo los actuales, por supuesto), con los de un exceso o abuso de la obligación de reciprocidad, causados precisamente en casos como el que nos ocupa por el impacto dogmático del librecambio ${ }^{46}$ colonizador.

46 Dicho sea de paso que procesos históricos de etnocidio como el andamanés ponen claramente de manifiesto el necesario acompañamiento de la fuerza armada al dogma del libre mercado. Sobre la ficción liberal del librecambismo pacífico : Ignasi Terradas (1980), "Orden social y Economía Política" Relaciones. El Colegio de Michoacán. México; y (1988), "La ficción liberal» en Mal natural, mal social. Barcelona: Barcanova. 
La concepción dogmática de la reciprocidad ha desarrollado todo un corolario de generalizaciones sobre la uinalienabilidad" de las cosas que se valoran como don, y ha dado lugar también a la confusión de la reciprocidad de don con la reciprocidad de contrato. Weiner es de las antropólogas que ha sostenido dicha generalización y confusión con más autoridad.

La reciprocidad de don es aquella que se explica por las tres acciones de Mauss: saber dar, saber recibir y saber retornar según determinados contextos sociales y culturales. Mientras que la reciprocidad de contrato radica exclusivamente en la obligación de cumplir con una materia determinada y sólo con ésta. Y aunque para cumplir con esa materia se evoquen o conjuren sentimientos morales de reciprocidad y vínculos personales estables, propios de otros compromisos, tal maniobra no sostiene la existencia social y sociable de la reciprocidad de don.

En comparación sociológica, la reciprocidad de don obliga por la vinculación existente entre las personas, mientras que la reciprocidad de contrato obliga por el poder que existe a compeler las partes sin ninguna otra vinculación que la del mismo contrato con su cumplimiento. Lo propio del don es ser un momento de una relación de vinculación. Lo propio del contrato es excluir la obligación de cualquier otra vinculación que no sea la del mismo contrato. Es por este motivo que toda la doctrina jurídica que descansa sobre una ética de vinculación entre personas según un ámbito determinado, se lleva mal con la contingencia contractual, y aún con la reciprocidad estricta ${ }^{47}$.

Por otra parte, hermanar una doctrina coherente y práctica de derechos humanos, respetuosos con varias vinculaciones, con un derecho mercantil extraordinariamente fragmentario es el imposible de la ideología liberal o librecambista de ahora y siempre.

Weiner ${ }^{48}$ también promueve la confusión entre el valor de cambio, el don y el objeto de culto. Este último es lo más distinto al objeto con valor de cambio. Cierto que determinados objetos se hallan en una frontera ambigua entre el culto, el don y el cambio. Pero precisamente esta ambigüiedad es propia de la crisis de una religión, de una tradición cultural o de una economía. Entonces se vende lo sagrado, se venden los regalos y se adora el dinero. $Y$ aun-

47 Cf. IGNASI TERRADAS (2002): "La reciprocidad superada por la equidad, el amor y la amistad". Madrid: Endoxa.

48 Op. cit., pp. 6-11. 
que esta crisis perdure y se extienda, se «normalice», no es motivo para anular nuestra capacidad crítica y analítica que la Antropología mantiene como método comparativo universal.

El malentendido de la reciprocidad matrimonial como una obligación gravosa de por sí ha ido aparejado con la representación de la mujer como víctima de esa misma reciprocidad. Aunque lo mismo puede decirse del hombre en el sentido del deber gravoso de cumplir con una alianza política antes que con una elección personal. Pero la idea lévi-straussiana de "circulación de mujeres" en la comunicación política masculina ha hecho más fortuna antropológica que la de la resignación masculina ante el deber político. Weiner critica la idea de Lévi-Strauss incluso en autoras como Ortner, Rubin y Strathern ${ }^{49}$ diciendo que continuan calificando a las mujeres como objetos sometidos al «esencialismo de la norma de reciprocidad».

Nos parece que la cuestión hay que enfocarla de otro modo. Es el abuso o la prescripción gravosa de la reciprocidad en la práctica matrimonial la que puede hacer pensar en que el matrimonio es la única o mejor forma de alianza y que las mujeres sólo contribuyen a la alianza y a la reciprocidad como esposas y madres. Pero un estudio contextualizado del mismo Parentesco desmiente este malentendido.

En este sentido la crítica de Weiner a Lévi-Strauss comienza bien. Es cierto que el esquema de reciprocidad de Lévi-Strauss ignora "las múltiples identidades de las mujeres y de los hombres como esposas y hermanas" ${ }^{50}$. Pero a partir de aquí Weiner pretende hacer un redescubrimiento de la teoría del Parentesco clasificatorio, el cual queda muy corto. Porque gran parte de esta teoría pre-lévi-straussiana es precisamente aquella a la que debemos el conocimiento de instituciones importantes de parentesco para la alianza política, $y$ que no se reducen al matrimonio. El avunculado y la solidaridad entre hermano y hermana son dos de ellas, y si no fuera por la propaganda que varios antropólogos han hecho para olvidar los estudios de Parentesco ${ }^{51}$, la misma

49 Op. cit., pp. 14.

50 Id., p. 15.

51 Los estudios de Parentesco son muy explícitos para constatar el etnocidio al que las «grandes civilizaciones" someten a muchos pueblos. Seguramente por este motivo resultan incómodos para los antropólogos que han abrazado la causa del imperialismo de mercado en nombre de la ficción de una ciudadanía mundial o una dignidad humana tan universal como individualista. 
Weiner no hubiera hecho el redescubrimiento, ni se habría atribuido el descubrimiento de lo que desde Rivers y Radcliffe-Brown sabemos: que la solidaridad entre hermano y hermana es fundamental en el parentesco clasificatorio, y que su extensionalidad atraviesa varias relaciones sociales y económicas muy importantes en las constituciones políticas de muchas sociedades.

También, la solidaridad entre hermanos y hermanas y el tabú del incesto son dos aspectos de un mismo ideal de afinidad. Con ellos se construye la exogamia cruzada: se casan entre sí los descendientes de un hermano y una hermana. La multiplicación de la alianza entre los descendientes es la contrapartida de la prohibición del incesto, más exigua en su ámbito. Es así como la afirmación de Lévi-Strauss de que la prohibición del incesto no lo es tanto en sí mismo sino como doctrina positiva de la exogamia, de la alianza, se ve reforzada al comprobar su efecto multiplicador entre líneas de descendencia.

Pero Weiner se empeña en tratar como antagónicas la solidaridad consanguínea y la prohibición del incesto. También lo hace con el matrimonio y la sexualidad, el linaje y la procreación, la familia y el hogar, el ajuar femenino y los trofeos masculinos... Francamente, nos parece que hacerlo a nivel conceptual puro, sin hacer referencia a casos concretos, confunde más que aclara. Esto es así porque los ejemplos etnográficos, como el andamanés, muestran la normalidad y el desarrollo de tales complementos y no su antagonismo.

Siguiendo la crítica que Mark Mosko ${ }^{52}$ hace a Weiner, podemos decir que la paradoja de "Inalienable Possessions" es la de comenzar criticando la noción de reciprocidad de Mauss-Malinowski (Que Weiner nunca define en el sistema de don tal como Mauss insistió) atribuyéndole un etnocentrismo que vendría a coincidir con la ideología del contrato liberal ${ }^{53}$. Y una vez

52 MARK S. MOSKO (2000): "Inalienable ethnography: keeping-while-giving and the Trobriand case». Journal of the Royal Anthropological Institute, $n .^{\circ} 6$.

53 La pretensión de Weiner es que la "norma de reciprocidad" procede de una teoría económica occidental forjada durante siglos y apropiada al desarrollo capitalista: «Durante la emergencia del capitalismo, el dar y tomar de la reciprocidad adquirió un poder sagrado, casi mágico, entre los economistas occidentales" (Weiner 1992,2). Por un lado Weiner no distingue algo más antiguo que el capitalismo moderno, "Remunerare solvere est, non donare», confunde pagar con dar. Por otro lado, no discute su hallazgo frente a Mauss, puesto que dicha "norma de reciprocidad" ajustada al mercado capitalista es del todo antitética con el sistema de don y la "moral de reciprocidad" de Mauss. Objetamos a Weiner que en el capitalismo el mercado no se regula de acuerdo con el principio de saber dar, recibir y retornar, sino con el de oferta y deman- 
dicho esto, Weiner la sustituye también con alcance universal, con el "guardar mientras se da" en una versión mucho más afín al individualismo posesivo, tan o más etnocéntrico (capitalista) que el contractualismo recíproco. En palabras de Mark Mosko: «Se toman las raíces occidentales de la teoría de la reciprocidad como indicios de distorsión a priori de la naturaleza que es propia de los sistemas de intercambio oceánicos (u otros), mientras que las raíces occidentales del "guardar mientras se da" revelan una lógica universal evidente de por sí.... ${ }^{54}$.

Mosko añade que Weiner no ve las "posesiones" o dominios sobre algo como un aspecto de las relaciones interpersonales (precisamente la característica propia de la reciprocidad como sistema del don decimos nosotros ), sino como relación inherente entre la cosa y su posesor.

Mosko, por su parte, reconduce la reciprocidad a sus propios términos como sistema social del don, no como individualismo contractualista: los objetos vinculan y desvinculan aspectos o cualidades de las personas; los contextos otorgan sentido a estas relaciones; las propiedades de los objetos intercambiados en la reciprocidad pueden ser igual o aún más ambivalentes que las personas (desde la gracia en el don hasta el veneno en el don); la «inalienabilidad" es una manera cosificada de referirse a la prioridad de las relaciones interpersonales, tal como sugiere Strathern; el significado de los objetos debe medirse para el conjunto de la vida de las personas no en el acto de su transmisión o intercambio; las claves de la "inalienabilidad" no están en los objetos sino en las personas y en los vínculos que establecen; en el sistema del don lo propio es dar, por lo tanto no hay "inalienabilidad" (a eso añadimos que dar no quiere decir alienar, como tampoco vender).

da, y que incluye la tierra, el dinero y el trabajo (Cf. Karl Polanyi (1944). The Great Transformation. Nueva York: Holt, Rinehart and Winston). Más concretamente, Weiner parece olvidar que precisamente para la Economía política clásica, el trabajo es el único bien que produce valor, y éste no recibe dones, sino que se remunera. Se paga según las fluctuaciones de su oferta y demanda, no según el principio del don. Por otra parte, el capital se invierte para obtener beneficios, no para desafiar con más improductividad a otros "capitales". Es decir que el mercado capitalista (por más "capital social» que consuma y destruya) no tiene nada que ver con los dones de una reciprocidad como la andamanesa, con los desaffos de la riqueza de un Potlatch, o con las obligaciones que aún van más allá de las reglas de la reciprocidad (Cf. Terradas (2002) "La reciprocidad superada por la equidad, el amor y la amistad" Endoxa. Madrid).

54 Op. cit., p. 378. 
En Antropología Social es más lógico entender la «inalienabilidad» como el poder de la vinculación personal, y enunciar este concepto en positivo.

Nos parece, pues, que el malentendido que ha hecho confundir la reforma de un tipo de reciprocidad con su total negación está relacionado con otro abuso o absolutismo más ordinario para la experiencia del antropólogo, y este es sin duda el de la economía contractual. Así entendemos mejor como Weiner, después de haber fusionado contrato y reciprocidad para el capitalismo occidental, encuentre natural el deseo absoluto de liberarse de esta "reciprocidad".

Pero la teoría antropológica no puede sostener esta fusión. Nos importa, y mucho, saber distinguir entre reciprocidad y contrato, en el sentido de sistema de don entre vinculaciones personales versus el interés o beneficio surgidos de la especificidad de cada intercambio o transacción, por más que éstos abusen del espíritu de reciprocidad de cualquiera de las partes implicadas.

Entendemos que en la sociedad de mercado el contrato abusa del espíritu y acción de la reciprocidad. Utiliza la intencionalidad de confianza, bondad y responsabilidad para abusar de las personas, haciéndolas creer en derechos humanos indisponibles, vínculos democráticos, cultura de valores, "amistad" y "familia» de empresa y negocios, estima y respeto al valor de cada persona, etc., cosas que día a día las escuelas de negocios incorporan a sus verdades mucho más groseras. Con esta programación ideológica se pretende que en una relación de mercado algunos se comporten dando de sí todo lo que pueden, confiados, responsables y muy generosos. Luego, cuando acontece la "verdad" de unas cuentas o el verdadero interés de un contrato, se esfuman todos esos valores tan enaltecidos de reciprocidad humana.

Comparemos toda la vitalidad humana que se pide al asalariado para identificarse y sacrificarse por la empresa o institución afín, con el nulo reconocimiento de su vida humana ante los caprichos de la ganancia, tales como la "flexibilidad del mercado" o la "crisis financiera".

Frente a políticos, negociantes y empresarios caprichosos con su nivel de ganancias, hay algunos que no cesan de reconocer el valor de la vida humana al cesar el valor del trabajo. Pero esto es una excepción contracorriente. Algo disonante para la misma legislación laboral y para toda la política económica del capitalismo caprichoso.

Criticar el contrato capitalista como abuso de la reciprocidad personal es un recurso metodológico fundamental para la comparación etnográfica e his- 
tórica. Creemos que tiene mucho sentido hablar de unas sociedades en las que la reciprocidad prevalece y de otras en las que lo hace el contrato. La valoración etnográfica de las tres fases maussianas de la reciprocidad (saber dar, saber recibir y saber devolver) en contextos, que además pueden superar a esta reciprocidad como norma, es algo muy relevante y que no hay que confundir con la reciprocidad contractual. Por ello queremos criticar esta fusión en obras como la de Weiner.

Por un lado, pues, la reciprocidad en el contrato es algo socio-lógicamente, culturalmente y éticamente distinto de la reciprocidad en el sistema de don. Pero hay otro aspecto de este malentendido global que conviene destacar: la confusión del regalo con la reciprocidad propiamente dicha en nuestra sociedad, dónde prevalece el contrato en el ordenamiento económico, político y jurídico. Por más que el regalo vaya asociado con una vinculación personal (amistad, amor...) propia de la reciprocidad-don y su existencia no dependa del interés contractual, al no ordenar ni establecer los principios de la propiedad y apropiación, no podemos hablar de sociedad de reciprocidad al referirnos a la nuestra. Conviene no olvidar que hasta que la propiedad con derecho registral, la contabilidad según precios, las rentas según costos, las inversiones según beneficios, los gastos según rendimientos y el valor del trabajo personal según el mercado laboral, no sean todos sustituidos por una reciprocidad según vinculaciones personales, el concepto teórico de reciprocidad no puede expresar ni los principios ni el ordenamiento económico y jurídico de nuestra sociedad. De ahí la relevancia metodológica de la distinción de Polanyi entre sociedad de mercado y sociedad de reciprocidad, caracterizando a los dos órdenes más extremos de la historia de la humanidad.

Por esto rechazamos también la pretensión de Weiner de asimilar el trabajo como fenómeno histórico a su valor de reciprocidad contractual según la Economía política occidental.

Para empezar, dar algo a cambio de otra cosa o perder un derecho para obtener una seguridad no es reciprocidad, tal como pretende Weiner ${ }^{55}$. Lo primero es intercambio, que es mucho menos que reciprocidad, y lo segundo es sometimiento, que aún es menos que contrato, aunque en muchos casos un abuso de hecho haga pasar al sometimiento como ejercicio de una libertad contractual. 
Cuando Marx atacaba la reciprocidad en la división del trabajo como fuente de alienación ${ }^{56}$ se estaba refiriendo a la reciprocidad contractual, ya que Marx no llegó a vislumbrar la reciprocidad descubierta por MaussMalinowski a partir del conocimiento etnográfico.

También hemos de comprender que el concepto antropológico de reciprocidad debe ir referido a contextos sociales específicos que normalmente lo superan ${ }^{57}$. La misma naturaleza de las vinculaciones entre objetos y personas debe ayudarnos a matizar mucho cada uso del concepto antropológico de reciprocidad. Cuando la vinculación es entre el cetro, la corona, los blasones y el rey, por ejemplo, sabemos que es de ámbito distinto a las vinculaciones entre un señor y sus tierras, o entre un colono y su heredero. La vinculación remite forzosamente a una relación especial entre las personas, y entre éstas y las cosas. Lo cual permite explicar que en el primer ejemplo es la relación rey-súbditos (que también es vinculante), en el segundo lo es la de señor-siervo, y en el tercero la de padre-heredero, las que determinan la "alienabilidad" de coronas, tierras y bienes del patrimonio útil. De hecho, jurídicamente, hay que hablar de fórmulas de sucesión, cabrevación y tradición respectivamente. Por lo tanto es más correcto hablar de las fórmulas especiales de transmisión de determinados bienes que de su presunta "inalienabilidad", tal como pretende Weiner. Porque los bienes aparecen como «inalienables» por contraste con la facilidad de su alienación en el mercado. Pero históricamente se trata de transmisiones o tradiciones de bienes con fórmulas que suelen dramatizar un cambio de relación personal o su trasmutación más definitiva. Así, no es lo mismo una compraventa en el mercado sin ningún ceremonial de vinculación y desvinculación ${ }^{58}$, que la vindicatio romana con todo este ceremonial; o el sistema Kula con su ceremonial de presentación de expectativas, ofrecimiento de dones, hospitalidad e intercambio paralelos, arte de recepción y entretenimiento,

56 Cf. WEINER, op. cit., p. 30.

57 Cf. I. TERRADAS «La reciprocidad superada por la equidad, el amor y la amistad». Endoxa. Madrid, 2002.

58 En cambio Weiner no comprende que lo que ella llama procedimientos «extremadamente complejos" y llenos de "requisitos", no son fórmulas para resistir la alienación de los bienes (“inalienabilidad») sino grandes creaciones de derecho y ritual para sostener los vínculos de antes y después de una transmisión. Esto es lo que hace que estemos ante una auténtica tradición, con todo el sentido de la palabra, una transmisión muy consciente de un bien y el recuerdo de los vínculos que ha conllevado, y todo el esfuerzo y aparato que se precisa para transformarlos o destruirlos. 
ostentación de prestigio y movilización de lealtades para cada uno des estos desafíos. $\mathrm{O}$ bien, en otro extremo, la misma conquista, que aparentemente sólo sustrae, usurpa y aniquila toda vinculación precedente, precisa poco a poco de toda una ideología legitimadora, la cual, muy a menudo acaba por reconocer también legitimidad en los vínculos precedentes. Sin ir más lejos podemos pensar cómo la conquista europea del Nuevo Mundo a medida que se ha ido legitimando en sí misma (civilización, riqueza, desarrollo, democracia) ha ido reconociendo también la legitimidad de los vínculos anteriores de quienes sufrieron el «derecho» de conquista. Ello ha dado lugar, por lo menos, a una confusión que medita entre la reparación simbólica, el arrepentimiento, el indigenismo y el deseo de rematar el "derecho" de conquista, como si se pudiera finiquitar con total desvinculación, igual que en una compraventa de mercado.

Tampoco es lo mismo la vinculación histórica entre personas que el dominio personal o personalísimo sobre las cosas. Así, no hay que confundir la ideología que defiende la conservación privilegiada de determinados bienes raíces $\mathrm{u}$ otros dominios de propiedad, con la que establece, por ejemplo, una fraternidad de sangre, aunque ambas se den en la misma sociedad y en la misma época, tal como ocurre en la época medieval.

Por otra parte, la idea de "inalienabilidad" centrada en los bienes, nos sustrae de la historia social propiamente dicha, de todo el significado y vicisitudes de diversos vínculos sociales, arrastrándonos en exceso hacia "la vida social de las cosas», en detrimento de la vida social de las personas. Muchos andamaneses escogieron estrechar aún más sus vínculos sociales, a riesgo de ser oprimidos por ellos, y acentuar su aislamiento, antes que quedar disueltos y exterminados por quienes faltaron a la reciprocidad como regla de trato entre pueblos libres.

\section{Bibliografía}

LA BIBLIA. Versió dels textos originals $i$ comentari (v.f.) Monestir de Montserrat.

La Sainte Bible (1961). París: Les éditions du Cerf.

Lévi-Strauss, Claude (1967): Les Structures Elémentaires de la Parenté. París: Mouton. Macpherson, Crawford Brough (1962): The Political Theory of Possessive Individualism. Oxford U.P. 
MAN, EDWARD HORACE (1932) (1885): On the Aboriginal Inhabitants of the Andaman Islands. Londres: Royal Anthropological Institute.

MAUSS, MARCEl (1950) (1923-24): en su Essai sur le Don. París: P.U.F.

MOSKO MARK (2000): «Inalienable ethnography: keeping-while-giving and the Trobriand case" Journal of the Royal Anthropological Institute.N. ${ }^{\circ} 6$.

PANDYA, VishVajIT (1993): Above the Forest. Delhi: Oxford U.P.

POLANY, KARL (1944): The Great Transformation. Nueva York : Holt, Rinehart and Winston.

RADCLIFFE-Brown, A.R. (1910): "Andamans. Puluga». Man. 2,17.

RadCliffe-Brown, A. R. (1964) (1922): The Andaman Islanders. New York: The Free Press.

Terradas, Ignasi (1980): «Orden social y Economía Política» Relaciones. El Colegio de Michoacán. México.

TERrADAS, IgNASI (1988): "La ficción liberal" en Mal natural, mal social. Barcelona:Barcanova.

TERRADAS, IgNaSI (2002): «La reciprocidad superada por la equidad, el amor y la amistad». Endoxa. Madrid.

TERrADAS, IGNASI (1998-1999): «Les cigales et le rythme des jours». Ecole Pratique des Hautes Etudes. Biologie et Evolution des Insectes, 1 1/12.

WeInER, ANNETTE (1992): Inalienable Possessions. The paradox of keping while giving. Berkeley: University of California Press. 